\title{
Correlation between Serum Uric Acid and Atherosclerotic Cardiovascular Complications in Patients with Systemic Lupus Erythematosus in Sohag University Hospital
}

\author{
Eman Ahmad Sabet, Sharaf Eldeen Shazly, Emad Ahmad Mohamad Yousef, Ahmad Mamdouh Taha \\ Department of Internal Medicine, Faculty of Medicine - Sohag University, Egypt \\ *Corresponding author: Ahmad Mamdouh Taha, Mobile: (+20) 01140140347, E-Mail: ahmadmamdouhtahaa@ yahoo.com
}

\begin{abstract}
Background: Systemic lupus erythematosus (SLE) has been associated with excess cardiovascular morbidity and mortality. The underlying causes of this phenomenon are still relatively unknown, but it is believed that a combination of classic and new cardiovascular risk factors including chronic low-grade inflammation may be involved.

Objective: This study was designed to assess the relationship between serum uric acid level and the CVD complications in SLE patients.

Patients and methods: This clinical-based prospective study was carried out on 60 patients. This study was conducted in Sohag University Hospital. The patients in the study were divided into two equal groups: Group (A) included patients with normal S.UA in between (2.4-6.0 mg/dl) for females and (3.4-7.0) for males and group (B) that included patients with elevated S.UA higher than the upper limit.

Results: Serum uric acid was significantly increased in patients with pulmonary hypertension than those who didn't develop pulmonary hypertension $(\mathrm{P}=0.02)$. serum uric acid level was insignificantly different as regards ECG and ECH findings except for segmental wall motion abnormality (SWMA) and pulmonary hypertension. There was a positive mild significant correlation between serum uric acid and cholesterol level $(r=0.35$ and $P=0.01)$ and duration of treatment $(\mathrm{r}=0.29$ and $\mathrm{P}=0.03)$, but insignificant with triglyceride level $(\mathrm{r}=0.22$ and $\mathrm{P}=0.08)$ and EULAR $\backslash$ ACR2019 score $(\mathrm{r}=0.01$ and $\mathrm{P}=093)$.

Conclusion: Higher serum uric acid levels are associated with global damage in patients with SLE. Serum uric acid was associated with arterial stiffness. Nevertheless, serum uric acid might be an ancillary indicator of subclinical atherosclerosis in SLE women with clinically evident atherosclerotic cardiovascular disease.
\end{abstract}

Keywords: Systemic Lupus Erythematosus, Serum Uric Acid, Atherosclerotic Cardiovascular.

\section{INTRODUCTION}

Systemic lupus erythematosus (SLE) is a complex autoimmune disease of unknown etiology, characterized by chronic immune activation and multiple immunologic phenotypes ${ }^{(1)}$. SLE can involve various organ systems, of which kidney involvement is a major concern, affecting about $50 \%$ of patients and accounting for significant morbidity and mortality in western countries, and the 5-years survival in SLE patients with renal involvement is very low even with treatment ${ }^{(2)}$. However, it has been reported that early diagnosis and prompt treatment may dramatically modify the course of renal disease and improve the long-term survival ${ }^{(3)}$. Therefore, early detection and diagnosis of lupus nephritis (LN) appear to be of great importance ${ }^{(4)}$.

Uric acid (UA) is a breakdown product of ingested and endogenously synthesized purines, which undergoes no further metabolism in humans and is excreted by the kidneys and the intestinal tract. It is well known that uric acid crystals are the causative agents of gout ${ }^{(5)}$.UA is capable of activating inflammasome, which plays an important role in some inflammatory responses including gout. However, a number of epidemiologic studies have reported that high uric acid levels in serum are associated with a wide variety of disorders, such as ischemic heart disease (IHD), cardiomyopathy and arrhythmia, hypertension, diabetes, insulin resistance, metabolic syndrome, and so on ${ }^{(3)}$. Furthermore, it has been found that although $29 \%$ of SLE patients were hyperuricemic, gout has rarely been reported in SLE patients ${ }^{(6)}$. On the other hand, some cases of coincidental SLE and gout had been reported associated with nephropathy, but the detailed association between elevated serum uric acid level and the development of lupus nephritis in SLE patients without gout remained unclear ${ }^{(7)}$.

Serum uric acid assays are clinically available and inexpensive. Clarification regarding whether SLE patients may benefit from uric acid being measured because of its possible role as a cardiovascular predictor is necessary. As far as we know, the potential link between serum uric acid and subclinical atherosclerosis it has not been explored in SLE. On the other hand, arterial stiffness is a marker for vascular dysfunction and an independent risk factor for cardiovascular diseases and this has been well validated in studies ${ }^{(\mathbf{8})}$.

This study was designed to assess the relationship between serum uric acid level and the CVD complications in SLE patients.

\section{PATIENTS AND METHODS}

This clinical based prospective study was carried out on 60 patients in Sohag University Hospital. 


\section{Inclusion criteria:}

Patients diagnosed as SLE according to diagnostic criteria of The 2019 European League Against Rheumatism/American College of Rheumatology (EULAR/ACR) ${ }^{(9)}$ classification criteria. The patients that were attending at the Outpatient Clinic or admitted in Internal Medicine Department of Sohag University Hospital were included after giving informed consents to participate in the study.

\section{Exclusion criteria:}

Patients below 18 years, previous history of valvular heart disease, elevated kidney functions (s.cr > $1.3 \mathrm{mg} / \mathrm{dl}$ in males and $>1.1 \mathrm{mg} / \mathrm{dl}$ in females), chronic obstructive pulmonary disease, gouty arthritis, and heart failure as a diagnosis clinically and by echocardiography.

\section{Ethical approval:}

Informed written consent was taken from every patient to include their data in the study. The study was approved by the Medical Ethics Committee of Sohag University Faculty of Medicine. This work has been carried out in accordance with The Code of Ethics of the World Medical Association (Declaration of Helsinki) for studies involving humans.

Most cases in the study were diagnosed as SLE (EULAR/ACR 2019 score $\geq 10$ ) without the need for further immunological investigations (Anti- phospholipid antibody, C3, C4, anti-dsDNA antibody and anti-Smith antibody).

The patients in the study were divided in to two equal groups: Group (A) patients with normal serum uric acid level in between $(2.4-6.0 \mathrm{mg} / \mathrm{dl})$ for female and (3.4-7.0) for male, and Group (B) patients with elevated serum uric acid level higher than the upper limit.

All patients included in the study were subjected to the following: Detailed history, full clinical examination, serum UA level, ECG, and transthoracic Doppler echocardiography. In selected cases: Stress ECG, coronary angiography, and carotid Doppler.

\section{Statistical analysis}

Data were analyzed using STATA version 14.2 (Stata Statistical Software: Release 14.2 College Station, TX: StataCorp LP.). Quantitative data were represented as mean, standard deviation, median and range. Data were analyzed using student t-test to compare means of two groups. When the data were not normally Mann-Whitney test was used. Qualitative data were presented as number and percentage and compared using either Chi square test or fisher exact test. Pearson's correlation was used to find correlation between different variables. Graphs were produced by using Excel or STATA program. $\mathrm{P}$ value $\leq 0.05$ is considered significant.

\section{RESULTS}

Table (1): Comparison between patient with normal and those with high s. uric acid as regards personal and medical history

\begin{tabular}{|c|c|c|c|}
\hline Variable & $\begin{array}{c}\text { Normal uric acid } \\
\mathbf{N}=\mathbf{3 0}\end{array}$ & $\begin{array}{c}\text { High uric acid } \\
\mathbf{N}=\mathbf{3 0}\end{array}$ & P value \\
\hline $\begin{array}{l}\text { Age /year } \\
\text { Mean } \pm \text { SD } \\
\text { Median (range) }\end{array}$ & $\begin{array}{c}29.83 \pm 8.98 \\
29(18: 45)\end{array}$ & $\begin{array}{c}31.6 \pm 8.68 \\
30.5(17: 45)\end{array}$ & 0.44 \\
\hline $\begin{array}{l}\text { Gender } \\
\text { Female } \\
\text { Male }\end{array}$ & $\begin{array}{c}28(93.33 \%) \\
2(6.67 \%)\end{array}$ & $\begin{array}{c}28(93.33 \%) \\
2(6.67 \%)\end{array}$ & 1.00 \\
\hline $\begin{array}{l}\text { History of DM } \\
\text { No } \\
\text { Yes }\end{array}$ & $\begin{array}{c}27(90.00 \%) \\
3(10.00 \%)\end{array}$ & $\begin{array}{c}26(86.67 \%) \\
4(13.33 \%)\end{array}$ & 1.00 \\
\hline $\begin{array}{l}\text { History of hypertension } \\
\text { No } \\
\text { Yes }\end{array}$ & $\begin{array}{c}28(93.33 \%) \\
2(6.67 \%) \\
\end{array}$ & $\begin{array}{c}27(90.00 \%) \\
3(10.00 \%) \\
\end{array}$ & 1.00 \\
\hline
\end{tabular}

The personal and medical history of the patients were insignificantly different between both groups (Table 1). 
Table (2): Comparison between patient with normal and those with high s. uric acid as regards presentation

\begin{tabular}{|l|c|c|c|}
\hline \multicolumn{1}{|c|}{ Variable } & $\begin{array}{c}\text { Normal uric acid } \\
\mathbf{N = 3 0}\end{array}$ & $\begin{array}{c}\text { High uric acid } \\
\mathbf{N = 3 0}\end{array}$ & P value \\
\hline Swelling of face & $10(33.33 \%)$ & $12(40.00 \%)$ & 0.59 \\
\hline Frothy urine & $17(56.67 \%)$ & $9(30.00 \%)$ & $\mathbf{0 . 0 4} *$ \\
\hline Ascites & $8(26.67 \%)$ & $6(20.00 \%)$ & 0.54 \\
\hline Pleural effusion & $9(30.00 \%)$ & $6(20.00 \%)$ & 0.37 \\
\hline Pitting edema over leg & $15(50.00 \%)$ & $10(33.33 \%)$ & 0.19 \\
\hline Hair loss & $14(46.67 \%)$ & $14(46.67 \%)$ & 1.00 \\
\hline Malar rash & $13(43.33 \%)$ & $12(40.00 \%)$ & 0.79 \\
\hline Discoid rash & $12(40.00 \%)$ & $6(20.000 \%)$ & 0.09 \\
\hline Photosensitivity & $16(53.33 \%)$ & $16(53.33 \%)$ & 1.00 \\
\hline Fever & $10(33.33 \%)$ & $17(56.67 \%)$ & 0.07 \\
\hline Oral ulcer & $21(70.00 \%)$ & $9(30.00 \%)$ & $\mathbf{0 . 0 0 2} *$ \\
\hline Arthritis & $20(66.67 \%)$ & $22(73.33 \%)$ & 0.57 \\
\hline Chest pain & 0 & $2(6.67 \%)$ & 0.49 \\
\hline
\end{tabular}

The frothy urine was significantly increased in normal uric acid group than high uric acid group $(\mathrm{p}=0.04)$. The oral ulcer was significantly increased in normal uric acid group than high uric acid group $(p=0.002)$. Presentation of the patients was insignificantly different between both groups except frothy urine and oral ulcer (Table 1).

Table (3): Comparison between patient with normal and those with high s. uric acid as regards Lab findings

\begin{tabular}{|l|c|c|c|}
\hline \multicolumn{1}{|c|}{ Variable } & $\begin{array}{c}\text { Normal uric acid } \\
\mathbf{N = 3 0} \\
\text { Mean } \pm \text { SD }\end{array}$ & $\begin{array}{c}\text { High uric acid } \\
\mathbf{N = 3 0} \\
\text { Mean } \pm \text { SD }\end{array}$ & P value \\
\hline ESR $(\mathrm{mm} / \mathrm{hr})$ & $13.16 \pm 3.88$ & $13.5 \pm 2.92$ & 0.62 \\
\hline WBCs $(\mathrm{mcL})$ & $6.0 \pm 1.92$ & $6.03 \pm 1.31$ & 0.74 \\
\hline HB $(\mathrm{g} / \mathrm{dL})$ & $10.47 \pm 1.57$ & $9.87 \pm 1.57$ & 0.14 \\
\hline PLTs $(\mathrm{mcL})$ & $218.77 \pm 9.56$ & $216.8 \pm 11.90$ & 0.87 \\
\hline Creatinine $(\mathrm{mg})$ & $0.87 \pm 0.20$ & $0.97 \pm 0.20$ & 0.12 \\
\hline Albumin $(\mathrm{g} / \mathrm{L})$ & $3.44 \pm 0.77$ & $3.40 \pm 0.77$ & 0.83 \\
\hline Cholesterol $(\mathrm{mg} / \mathrm{dL})$ & $146.03 \pm 18.71$ & $166 \pm 30.75$ & $\mathbf{0 . 0 0 4} *$ \\
\hline Triglyceride $(\mathrm{mg} / \mathrm{dL})$ & $134.9 \pm 7.65$ & $139.67 \pm 12.77$ & 0.07 \\
\hline Anti-dsDNA & $6(20.00 \%)$ & $9(30.00 \%)$ & 0.37 \\
Negative & $24(80.00 \%)$ & $21(70.00 \%)$ & \\
Positive & $10(33.33 \%)$ & $9(30.00 \%)$ & 0.78 \\
\hline Antinuclear antibody (ANA) & $20(66.67 \%)$ & $21(70.00 \%)$ & \\
Negative & & & \\
Positive & &
\end{tabular}

Lab findings were insignificantly different between both groups except cholesterol which was significantly decreased in normal uric acid group than high uric acid group $(\mathrm{P}=0.004)$ (Table 3$)$.

Table (4): Comparison between patient with normal and those with high s. uric acid as regards renal biopsy

\begin{tabular}{|l|c|c|c|}
\hline \multicolumn{1}{|c|}{ Variable } & $\begin{array}{c}\text { Normal uric acid } \\
\mathbf{N = 3 0}\end{array}$ & $\begin{array}{c}\text { High uric acid } \\
\mathbf{N = 3 0}\end{array}$ & P value \\
\hline Not done & $5(16.67 \%)$ & $5(16.67 \%)$ & \\
Minimal change disease & $9(30.00 \%)$ & $9(30.00 \%)$ & \\
Focal segmental glomerulosclerosis & $1(3.33 \%)$ & $1(3.33 \%)$ & \\
Diffuse proliferative & $3(1.00 \%)$ & $3(10.00 \%)$ & 1.00 \\
Membranous nephropathy & $2(6.67 \%)$ & $2(6.67 \%)$ & \\
Membranoproliferative glomerulonephritis & $1(3.33 \%)$ & $1(3.33 \%)$ & \\
Sclerosing glomerulonephritis & $1(3.33 \%)$ & $1(3.33 \%)$ & \\
Minimal mesangial & $1(3.33 \%)$ & $1(3.33 \%)$ & \\
Mesangial proliferative & $2(6.67 \%)$ & $2(6.67 \%)$ & \\
Crescent glomerulonephritis & $2(6.67 \%)$ & $2(6.67 \%)$ & \\
Amyloidosis & $2(6.67 \%)$ & $2(6.67 \%)$ & \\
\hline
\end{tabular}

The renal biopsy of the patients was insignificantly different between both groups (Table 4). 
Table (5): Comparison between patient with normal and those with high s. uric acid as regards EULAR\ACR2019 SCORE of studied population

\begin{tabular}{|l|c|c|c|}
\hline \multicolumn{1}{|c|}{ Variable } & $\begin{array}{c}\text { Normal uric acid } \\
\mathbf{N = 3 0}\end{array}$ & $\begin{array}{c}\text { High uric acid } \\
\mathbf{N}=\mathbf{3 0}\end{array}$ & P value \\
\hline EULAR\ACR2019 SCORE & & & \\
Mean \pm SD & $16.73 \pm 2.80$ & $16.57 \pm 3.65$ & 0.84 \\
Median (range) & $17(11: 24)$ & $16.5(11: 25)$ & \\
\hline
\end{tabular}

EULAR\ACR2019 SCORE of studied population was insignificantly different between both groups (Table 5).

Table (6): Comparison between patient with normal and those with high s. uric acid as regards ECG and Echo finding of studied population

\begin{tabular}{|l|c|c|c|}
\hline \multicolumn{1}{|c|}{ Variable } & $\begin{array}{c}\text { Normal uric acid } \\
\mathbf{N = 3 0}\end{array}$ & $\begin{array}{c}\text { High uric acid } \\
\mathbf{N = 3 0}\end{array}$ & P value \\
\hline ST segment depression & $1(3.33 \%)$ & $4(13.33 \%)$ & 0.353 \\
\hline Mitral valve regurgitation & $1(3.33 \%)$ & $4(13.33 \%)$ & 0.353 \\
\hline Aortic valve stenosis & 0 & $1(3.33 \%)$ & 1.00 \\
\hline Ejection fraction & $30(100 \%)$ & $24(80.00 \%)$ & \\
Normal & 0 & $3(10.00 \%)$ & \\
$45-55 \%$ & 0 & $3(10.00 \%)$ & \\
$30-45 \%$ & $1(3.33 \%)$ & $6(20.00 \%)$ & $\mathbf{0 . 0 4} *$ \\
\hline Segmental wall motion abnormality & & & \\
(SWMA) & $1(3.33 \%)$ & $6(20.00 \%)$ & $\mathbf{0 . 0 4} *$ \\
\hline Pulmonary hypertension & & & \\
\hline
\end{tabular}

The ejection fraction (EF) was significantly increased in normal uric acid group than in high uric acid group $(\mathrm{p}$ $=0.04)$. The SWMA was significantly decreased in normal uric acid group than in high uric acid group $(p=\mathbf{0 . 0 4})$. The pulmonary hypertension was significantly decreased in normal uric acid group than in high uric acid group $(\mathrm{p}=\mathbf{0 . 0 4})$. ECG and Echo findings of studied population were insignificantly different between both groups except ejection fraction, SWMA and pulmonary hypertension (Table 6).

Table (7): Comparison between patient with normal and those with high s. uric acid as regards treatment and disease activity

\begin{tabular}{|c|c|c|c|}
\hline Variable & $\begin{array}{c}\begin{array}{c}\text { Normal uric acid } \\
\mathbf{N}=\mathbf{3 0}\end{array} \\
\end{array}$ & $\begin{array}{c}\text { High uric acid } \\
\mathrm{N}=\mathbf{3 0}\end{array}$ & $P$ value \\
\hline $\begin{array}{l}\text { Initial treatment } \\
\text { Steroid } \\
\text { ACE inhibitor }\end{array}$ & $\begin{array}{c}26(86.67 \%) \\
4(13.33 \%)\end{array}$ & $\begin{array}{c}24(80.00 \%) \\
6(20.00 \%)\end{array}$ & 0.49 \\
\hline $\begin{array}{l}\text { Duration of treatment (months) } \\
\text { Mean } \pm \text { SD } \\
\text { Median (range) } \\
\end{array}$ & $\begin{array}{c}7.8 \pm 4.31 \\
7(1: 21) \\
\end{array}$ & $\begin{array}{l}10.37 \pm 5.57 \\
9.5(3: 30)\end{array}$ & $0.047 *$ \\
\hline $\begin{array}{l}\text { Last treatment } \\
\text { Steroid } \\
\text { Azathioprine } \\
\text { Cyclophosphamide } \\
\text { Cyclosporine } \\
\text { Steroid + azathioprine } \\
\text { Steroid + cyclophosphamide } \\
\text { Steroid + azathioprine + cyclophosphamide } \\
\text { Steroid + cyclosporine } \\
\text { Stopped treatment }\end{array}$ & $\begin{array}{c}3(10.00 \%) \\
3(10.00 \%) \\
1(3.33 \%) \\
4(13.33 \%) \\
3(10.00 \%) \\
3(10.00 \%) \\
4(13.33 \%) \\
5(16.67 \%) \\
3(10.00 \%)\end{array}$ & $\begin{array}{c}3(10.00 \%) \\
3(10.00 \%) \\
1(3.33 \%) \\
3(10.00 \%) \\
3(10.00 \%) \\
3(10.00 \%) \\
5(16.67 \%) \\
5(16.67 \%) \\
3(10.00 \%)\end{array}$ & 1.00 \\
\hline $\begin{array}{l}\text { On treatment of SLE now } \\
\text { No } \\
\text { Yes }\end{array}$ & $\begin{array}{c}1(3.33 \%) \\
29(96.67 \%)\end{array}$ & $\begin{array}{c}1(3.33 \%) \\
29(96.67 \%)\end{array}$ & 1.00 \\
\hline $\begin{array}{l}\text { Activity } \\
\text { No } \\
\text { Yes }\end{array}$ & $\begin{array}{c}28(93.33 \%) \\
2(6.67 \%)\end{array}$ & $\begin{array}{c}28(93.33 \%) \\
2(6.67 \%)\end{array}$ & 1.00 \\
\hline
\end{tabular}

The duration of treatment was significantly decreased in normal uric acid group than in high uric acid group $(\mathrm{p}$ $=0.047$ ). Treatment and disease activity were insignificantly different between both groups except duration of treatment that was shorter in normal uric acid group (Table 7). 
Table (8): Correlation between S. uric acid and some important factors

\begin{tabular}{|l|c|c|}
\hline \multicolumn{1}{|c|}{ Variable } & $\begin{array}{c}\text { Correlation co- } \\
\text { efficient (r) }\end{array}$ & $\begin{array}{c}\text { P } \\
\text { value }\end{array}$ \\
\hline Cholesterol level & 0.35 & 0.01 \\
\hline Triglyceride level & 0.22 & 0.08 \\
\hline $\begin{array}{l}\text { Duration of } \\
\text { treatment }\end{array}$ & 0.29 & 0.03 \\
\hline $\begin{array}{l}\text { EULAR\ACR2019 } \\
\text { score }\end{array}$ & 0.01 & 0.93 \\
\hline
\end{tabular}

There was a positive mild significant correlation between serum uric acid and cholesterol level $(\mathrm{r}=0.35$ and $\mathrm{P}=0.01)$. There was an insignificant correlation between serum uric acid and triglyceride level $(r=0.22$ and $P=0.08)$. There was a positive mild significant correlation between serum uric acid and duration of treatment $(r=0.29$ and $\mathrm{P}=0.03)$. There was an insignificant correlation between serum uric acid and EULAR\ACR2019 score $(r=0.01$ and $P=0.93)$ (Table $8)$.

\section{Discussion:}

The personal and medical histories of the patients were insignificantly different between both groups. The frothy urine was significantly increased in normal uric acid group than high uric acid group $(\mathrm{p}=$ $0.04)$. The oral ulcer was significantly increased in normal uric acid group than high uric acid group ( $\mathrm{p}=$ 0.002). Presentation of the patients was insignificantly different between both groups except for frothy urine and oral ulcer. However, in the study of Sabio et al. ${ }^{(10)}$, there was statistically significant difference among both groups as regards age and duration of disease.

The association between uric acid levels and damage accrual in patients with SLE was evaluated, and serum uric acid level was found to be associated with the development of new damage in these patients. Previous studies have found an association between hyperuricemia and hypertension, metabolic syndrome and renal disease, as well as with organ failure or damage, especially renal ${ }^{(\mathbf{1 1})}$.

The present study showed that lab findings were insignificantly different between both groups except for cholesterol, which was significantly decreased in normal uric acid group than in high uric acid group $(\mathrm{P}=0.004)$. The renal biopsy of the patients was insignificantly different between both groups. The urine examination of the patients was insignificantly different between both groups. EULAR\ACR2019 SCORE of studied population was insignificantly different between both groups. In SLE, serum uric acid levels have been reported to be associated with several impairments, including renal, cardiovascular, pulmonary and neurological, which when analyzed together may explain the impact on damage. Yang et al. (12) found that serum uric acid level was associated with the development of lupus nephritis. Previously, Reátegui-Sokolova et al. ${ }^{\left({ }^{(3)}\right)}$ have reported that serum uric acid level predicts increased kidney damage. In the same way, Ugolini-Lopes et al. ${ }^{(14)}$ found that serum uric acid levels $<6.05 \mathrm{mg} / \mathrm{dL}$ at 12 months of follow-up were a predictor of good long-term renal outcome in lupus nephritis.

Serum uric acid levels have an association with surrogate markers of atherosclerosis in a number of studies. Surrogate markers of atherosclerosis shown to have an association with hyperuricemia including carotid intima-media thickness (C-IMT), ankle brachial index, coronary artery calcification, and brachial-ankle pulse wave velocity (baPWV). In addition, many studies suggest an independent effect of elevated serum uric acid on atherosclerosis as measured by these surrogate markers after adjusting for the influence of metabolic syndrome and other factors. In particular, there is evidence that uric acid has direct effects on key processes involved in endothelial function and vascular remodeling ${ }^{(15)}$.

As noted above, uric acid has both prooxidant and antioxidant activity. When acting an antioxidant, it chelates metals and scavenges oxygen radicals. As a prooxidant, uric acid oxidizes lipids, reduces nitric oxide availability in endothelial cells, and increases reactive oxygen species. Furthermore, as a prooxidant, high levels of serum uric acid cause increased lipid oxidation. The resultant inflammation would be expected to disrupt reverse cholesterol transport, a function that is important to reduce cardiovascular risk (16).

Oxidants also cause endothelial dysfunction by reacting with and removing NO, thereby preventing vasodilation of the endothelium. Decreased NO and increased reactive oxygen species may promote a proinflammatory state that causes endothelial dysfunction and contributes to atherosclerosis and cardiovascular disease. Finally, uric acid inhibits endothelial cell proliferation and stimulates C-reactive protein production in endothelial cells ${ }^{(\mathbf{1 7})}$.

The current study showed that the ejection fraction $(\mathrm{EF})$ was significantly increased in normal uric acid group than in high uric acid group $(p=0.04)$. The SWMA was significantly decreased in normal uric acid group than in high uric acid group $(\mathrm{p}=0.01)$. The pulmonary hypertension was significantly decreased in normal uric acid group than in high uric acid group $(\mathrm{p}=$ 0.01). ECG and ECH finding of studied population were insignificantly different between both groups except EF, SWMA and Pulmonary hypertension.

Serum uric acid was significantly increased in patients with SWMA than in patients without SWMA $(P=0.02)$. Serum uric acid was significantly increased in patients with pulmonary hypertension than in those who didn't develop pulmonary hypertension $(\mathrm{P}=0.02)$. Serum uric acid level was insignificantly different as regards ECG and ECH findings except for SWMA and pulmonary hypertension.

Our results are in agreement with study of Sabio et al. ${ }^{(\mathbf{1 0})}$, as they reported that uric acid levels 
were significantly associated with arterial stiffness after adjustment for conventional cardiovascular risk factors, SLE-related factors and inflammation markers in women with SLE. Women with SLE and HU (n $1 / 4$ 15, $15 \%$ ) had a worse cardiovascular risk profile that included ageing, hypertension, obesity, higher total cholesterol levels, renal failure and presence of metabolic syndrome. Also, the duration of SLE was increased and damage accrual was greater. In the unadjusted analysis, serum uric acid levels correlated with PWV (pulse wave velocity), CRP, fibrinogen and homocysteine. However, in a multivariate linear regression analysis, serum uric acid levels independently correlated with the duration of SLE, creatinine, total cholesterol and homocysteine levels but did not correlate with PWV. Similarly, CastilloMartínez et al. ${ }^{(18)}$ demonstrated that serum uric acid levels greater than $7 \mathrm{mg} / \mathrm{dL}$ would increase the risk of developing pulmonary hypertension by 8.5 times. Similar findings have been reported by Kim et al. ${ }^{(19)}$ where a value greater than $6.5 \mathrm{mg} / \mathrm{dL}$ of uric acid would be reasonably accurate in predicting the presence of pulmonary hypertension. In addition, hyperuricemia has been shown to be related to factors that would increase the risk of stroke, such as high blood pressure, hyperlipidemia and history of arterial thrombosis, and has been independently associated with the occurrence of cerebrovascular events and polyneuropathy ${ }^{(20)}$.

Numerous epidemiological studies have described a link between hyperuricemia and CVD. Recently, Borghi et al. ${ }^{(21)}$ conducted a comprehensive review of hyperuricemia and cardiovascular morbidity and/or mortality; however, most of these studies did not include vascular stiffness as a surrogate endpoint. Four large epidemiological transversal studies including more than 1,000 patients with differences in clinical characteristics showed a positive association between serum uric acid and vascular stiffness, assessed for the most part by carotid-femoral PWV (cfPWV) ${ }^{(22,23)}$. In patients with SLE, uric acid has been recognized as a potential marker of endothelial dysfunction and renal disease, as an association has been found between active lupus nephritis and hyperuricemia, as well as with cerebral infarction and peripheral neuropathy. Likewise, uric acid levels are useful in predicting the future development of pulmonary hypertension in patients with SLE with normal basal systolic pulmonary artery pressure. In addition, serum uric acid levels have been reported as predictor of increased risk of kidney damage ${ }^{(24)}$.

There was a positive mild significant correlation between serum uric acid and cholesterol level $(r=0.35$ and $P=0.01)$. There was a positive mild significant correlation between serum uric acid and triglyceride level $(\mathrm{r}=0.22$ and $\mathrm{P}=0.08)$. There was a positive mild significant correlation between serum uric acid and duration of treatment $(\mathrm{r}=0.29$ and $\mathrm{P}=0.03)$. There was a positive mild insignificant correlation between serum uric acid and EULAR\ACR2019 score $(\mathrm{r}=0.01$ and $\mathrm{P}=0.93)$.

In the study in our hands, the duration of treatment was significantly decreased in normal uric acid group than in high uric acid group $(\mathrm{p}=0.047)$. Treatment and disease activity were insignificantly different between both groups except duration of treatment. Taraborelli et al. ${ }^{(25)}$ examined the effect of disease duration of 511 patients with SLE on damage. This study showed that, at 1 year of follow-up, about $40 \%$ of patients had some damage usually mild or moderate. The prevalence of damage progressively increased over time, starting from a mean SDI score of 0.6 (SD: 0.89 ) at 1 year to 0.9 (SD: 1.19) at 5 years and 3.7 (SD: 1.5) at 35 years of follow-up. Bruce et al. ${ }^{(26)}$ found that increasing age had a significant influence on the probability of damage accrual, and is also the case for ethnicity. For example, compared to Caucasians from Europe or Canada, US patients of African ancestry had a higher risk of evolving from no damage to damage and also of progressing from baseline damage to higher damage, and the case is the same for Hispanic patients (27). Moreover, Shaharir et al. (28) investigated the associated factors of disease damage among patients with lupus nephritis and found that higher daily prednisolone dose predicted disease damage.

Keeping uric acid levels low is recommended to avoid damage in SLE, as it has been observed in studies that increasing uric acid is related to anemia in SLE, and also associated with the occurrence of stroke, peripheral neuropathy, hypertension, hyperlipidemia and history of arterial thrombosis. Even normal values of uric acid have been associated with renal damage in patients with SLE ${ }^{(29)}$.

\section{CONCLUSIONS}

Higher serum uric acid levels are associated with global damage in patients with SLE. Serum uric acid was associated with arterial stiffness. Nevertheless, serum uric acid might be an ancillary indicator of subclinical atherosclerosis in SLE women with clinically evident atherosclerotic cardiovascular disease.

\section{Financial support and sponsorship: Nil. Conflict of interest: Nil.}

\section{REFERENCES}

1. Fairhurst A, Wandstrat A, Wakeland E (2006): Systemic lupus erythematosus: multiple immunological phenotypes in a complex genetic disease. Adv Immunol., 92: 1-69.

2. Korbet S, Lewis E, Schwartz $M$ et al. (2000): Factors predictive of outcome in severe lupus nephritis. Lupus Nephritis Collaborative Study Group. Am J Kidney Dis., 35 (5): 904-14.

3. Feig D, Kang D, Johnson $\mathbf{R}$ (2008): Uric acid and cardiovascular risk. N Engl J Med., 359 (17): 1811-21.

4. Esdaile J, Joseph L, MacKenzie T et al. (1994): The benefit of early treatment with immunosuppressive 
agents in lupus nephritis. J Rheumatol., 21 (11): 204651.

5. Martinon F, Pétrilli V, Mayor A et al. (2006): Goutassociated uric acid crystals activate the NALP3 inflammasome. Nature., 440 (7081): 0237-41.

6. Ho H, Lin J, Wu Y et al. (2003): Gout in systemic lupus erythematosus and overlap syndrome - a hospital-based study. Clin Rheumatol., 22 (4-5): 295-8.

7. Pu S, Luo S, Wu Y et al. (2000): The clinical features and prognosis of lupus with disease onset at age 65 and older. Lupus, 9 (2): 96-100.

8. Mattace-Raso F, van der Cammen T, Hofman A et al. (2006): Arterial stiffness and risk of coronary heart disease and stroke: the Rotterdam Study. Circulation, 113 (5): 657-63.

9. Aringer M, Costenbader K, Daikh D et al. (2019): 2019 European League Against Rheumatism/American College of Rheumatology Classification Criteria for Systemic Lupus Erythematosus. Arthritis Rheumatol., 71 (9): 1400-1412.

10. Sabio J, Vargas-Hitos J, Mediavilla J et al. (2010): Correlation of asymptomatic hyperuricaemia and serum uric acid levels with arterial stiffness in women with systemic lupus erythematosus without clinically evident atherosclerotic cardiovascular disease. Lupus, 19 (5): 591-8.

11. Konta T, Kamei K, Ichikawa $K$ et al. (2018): The Association between Serum Uric Acid and Renal Damage: The Takahata Study - New Insights. Contrib Nephrol., 192: 34-40.

12. Yang Z, Liang Y, Xi W et al. (2011): Association of serum uric acid with lupus nephritis in systemic lupus erythematosus. Rheumatol Int., 31 (6): 743-8.

13. Reátegui-Sokolova $C$, Ugarte-Gil $M$, GamboaCárdenas $\mathrm{R}$ et al. (2017): Serum uric acid levels contribute to new renal damage in systemic lupus erythematosus patients. Clin Rheumatol., 36 (4): 845-52.

14. Ugolini-Lopes M, Gavinier S, Leon E et al. (2019): Is serum uric acid a predictor of long-term renal outcome in lupus nephritis? Clin Rheumatol., 38 (10): 2777-83.

15. Kang D, Park S, Lee I et al. (2005): Uric acid-induced C-reactive protein expression: implication on cell proliferation and nitric oxide production of human vascular cells. J Am Soc Nephrol., 16 (12): 3553-62.

16. McGillicuddy F, de la Llera Moya M, Hinkle C et al. (2009): Inflammation impairs reverse cholesterol transport in vivo. J Circulation, 119 (8): 1135.

17. Kanellis J, Watanabe $\mathrm{S}, \mathrm{Li} \mathbf{J}$ et al. (2003): Uric acid stimulates monocyte chemoattractant protein-1 production in vascular smooth muscle cells via mitogen- activated protein kinase and cyclooxygenase-2. J Hypertension, 41 (6): 1287-93.

18. Castillo-Martínez D, Marroquín-Fabián E, LozadaNavarro A et al. (2016): Levels of uric acid may predict the future development of pulmonary hypertension in systemic lupus erythematosus: a seven-year follow-up study. Lupus, 25 (1): 61-6.

19. Kim K, Baek I, Park Y et al. (2015): High levels of uric acid in systemic lupus erythematosus is associated with pulmonary hypertension. Int J Rheum Dis., 18 (5): 52432.

20. Sheikh M, Movassaghi S, Khaledi M et al. (2016): Hyperuricemia in systemic lupus erythematosus: is it associated with the neuropsychiatric manifestations of the disease? Rev Bras Reumatol Engl Ed., 56 (6): 471-7.

21. Borghi C, Rosei E, Bardin T et al. (2015): Serum uric acid and the risk of cardiovascular and renal disease. $\mathbf{J}$ Hypertens., 33 (9): 1729-41.

22. Fang J, Wu J, Yang Y et al. (2014): High uric acid level associated with increased arterial stiffness in apparently healthy women. Atherosclerosis, 236 (2): 389-93.

23. Mehta T, Nuccio E, McFann $K$ et al. (2015): Association of uric acid with vascular stiffness in the Framingham heart study. Am J Hypertens., 28 (7): 87783.

24. Calich A, Borba E, Ugolini-Lopes $M$ et al. (2018): Serum uric acid levels are associated with lupus nephritis in patients with normal renal function. Clin Rheumatol., 37 (5): 1223-8.

25. Taraborelli M, Cavazzana I, Martinazzi $\mathbf{N}$ et al. (2017): Organ damage accrual and distribution in systemic lupus erythematosus patients followed-up for more than 10 years. Lupus, 26 (11): 1197-204.

26. Bruce I, O'Keeffe A, Farewell V et al. (2015): Factors associated with damage accrual in patients with systemic lupus erythematosus: results from the Systemic Lupus International Collaborating Clinics (SLICC) Inception Cohort. Ann Rheum Dis., 74 (9): 1706-13.

27. Alarcón G, McGwin G, Bertoli A et al. (2007): Effect of hydroxychloroquine on the survival of patients with systemic lupus erythematosus: data from LUMINA, a multiethnic US cohort (LUMINA L). Ann Rheum Dis., 66 (9): 1168-72.

28. Shaharir S, Ghafor A, Said M et al. (2014): A descriptive study of the factors associated with damage in Malaysian patients with lupus nephritis. Lupus, 23 (4): 436-42.

29. Yang Z, Liang Y, Li C et al. (2012): Associations of serum urea, creatinine and uric acid with clinical and laboratory features in patients with systemic lupus erythematosus. Rheumatol Int., 32 (9): 2715-23. 